\title{
Treatment of diabetic nephropathy with Tripterygium wilfordii Hook F extract: a prospective, randomized, controlled clinical trial
}

\author{
Yongchun Ge, Honglang Xie, Shijun Li, Bo Jin, Jinhua Hou, Haitao Zhang, Mingjun Shi and Zhihong Liu*
}

\begin{abstract}
Background: Diabetic nephropathy (DN) is the most common cause of end-stage renal failure. Although angiotensin II receptor blockers (ARBs) can be used to attenuate proteinuria in DN patients, their efficacy remains limited. This clinical trial aimed to evaluate the efficacy of Tripterygium wilfordii Hook F (TwHF) extract in the treatment of type 2 diabetes mellitus (DM)-induced nephropathy.
\end{abstract}

Methods: A total of $65 \mathrm{DN}$ patients with proteinuria levels $\geq 2.5 \mathrm{~g} / 24 \mathrm{~h}$ and serum creatinine levels $<3 \mathrm{mg} / \mathrm{dl}$ were enrolled in this six-month, prospective, randomized, controlled study. The patients were randomized into treatment groups that received either $120 \mathrm{mg}$ of TwHF extract per day for three months, followed by $60 \mathrm{mg}$ per day for three more months, or $160 \mathrm{mg}$ of valsartan daily for six months. The urinary protein and estimated glomerular filtration (eGFR) level were measured at one, three, and six months after the commencement of treatment. The primary measure of treatment efficacy was a reduction in the 24-h urine protein level between baseline and the end of the study, and the secondary measure of treatment efficacy was a reduction in the eGFR value.

Results: At the end of the treatment period, the mean urine protein level in the TwHF group was dramatically decreased $(4.99 \pm 2.25 \mathrm{~g} / 24 \mathrm{~h}$ vs $2.99 \pm 1.81 \mathrm{~g} / 24 \mathrm{~h}, \mathrm{p}<0.01)$, with decreases at one, three, and six months of 32.9\%, $38.8 \%$, and $34.3 \%$, respectively. In contrast, the proteinuria in the valsartan group was not significantly attenuated, and the decreases in urine protein levels at treatment months one, three, and six were $1.05 \%, 10.1 \%$, and $-11.7 \%$, respectively. The mean decrease in eGFR in the valsartan group was greater than that in the TwHF group (26.4\% vs. $13.7 \%$, respectively; $p=0.067$ ).

Conclusions: TwHF extract can reduce the urine protein level of DN patients and represents a novel, potentially effective, and safe drug for the treatment of DN patients with proteinuria.

Trial registration: ClinicalTrials.gov: NCT00518362

Keywords: Type 2 diabetes mellitus, Diabetic nephropathy, Proteinuria, Tripterygium wilfordii Hook F (TwHF), Angiotensin II receptor blocker (ARB)

\section{Background}

Diabetes mellitus (DM) is a major public health issue in China. With the rapidly changing lifestyle of the general Chinese population, there is increasing concern that diabetes may become an epidemic [1]. The impact of diabetic nephropathy $(\mathrm{DN})$ in China has been evidenced by our previous studies, in which examinations of renal biopsies revealed that the incidence of DN was 1.68 -fold

\footnotetext{
* Correspondence: zhihong-liu@hotmail.com

Reasch Institute of nephrology, Jinling Hospital, Nanjing University school of medicine, Nanjing, China
}

the level over a decade previously [2]. DN has become a common cause of end-stage renal disease (ESRD) in China.

Persistent proteinuria is a hallmark of $\mathrm{DN}$ and an independent risk factor for $\mathrm{DN}$ progression and $\mathrm{DN}$ related cardiovascular events [3]. Therefore, improvement of proteinuria is as important as control of blood glucose and blood pressure for patients with DN [4]. Several multicenter, prospective, randomized, controlled clinical trials have confirmed that renin-angiotensin system (RAS) blockades with angiotensin II receptor 
blockers (ARBs) can reduce the urine protein level in patients with DN and may confer additional benefits for renal function [5,6]. However, the efficacy of the currently available ARBs for attenuating proteinuria is insufficient, particularly for DM patients who present with extensive proteinuria and renal dysfunction. Therefore, it is imperative to develop novel strategies to decrease proteinuria to prevent the progression of $\mathrm{DN}$.

Tripterygium wilfordii Hook F (TwHF) extract is a traditional Chinese medicine that has been used for many years in glomerulonephritis treatment and organ transplantation $[7,8]$, likely for its immunosuppressive and anti-inflammatory effects [9]. Consistent with this traditional use, Goldbach-Mansky and colleagues have reported that TwHF extract is also effective and safe for the treatment of rheumatoid arthritis [10]. Our recent in vitro and in vivo studies have shown that triptolide (the primary active component of the TwHF extract) protects podocytes from injury $[11,12]$ and ameliorates the albuminuria exhibited by $\mathrm{db} / \mathrm{db}$ mice, effects that are likely due to its podocyte-protective and antiinflammatory effects [13].

We conducted a clinical trial to explore the use of TwHF extract in the treatment of DN. This single-center, prospective, randomized, controlled trial was conducted from March 2007 to April 2010 and was registered at ClinicalTrial.gov (identifier: NCT 00518362). The aim of this study was to evaluate the efficacy and safety of TwHF and valsartan for reducing proteinuria in $\mathrm{DN}$ patients.

\section{Methods}

\section{Patient selection}

The inclusion criteria were patients 30-65 years of age with a diagnosis of type $2 \mathrm{DM}$, proteinuria (urine protein $\geq 2.5 \mathrm{~g} / 24 \mathrm{~h}$ ), and serum creatinine levels of $<3 \mathrm{mg} / \mathrm{dl}$. The diagnosis of DN was confirmed either by the pathological examination of a renal biopsy performed within six months prior to study enrollment or by the presence of clinical manifestations (if a renal biopsy was unavailable). The local ethics committee of Jinling Hospital approved the protocol, and all the enrolled patients provided written informed consent prior to the study. The exclusion criteria included a diagnosis of type $1 \mathrm{DM}$, nondiabetic kidney disease, liver function impairment (alanine aminotransferase or aspartate aminotransferase levels $>$ twofold the upper limit of normal), a white blood cell (WBC) count $<3.0 \times 10^{9} / \mathrm{L}$, severe hypertension (blood pressure $>180 / 100 \mathrm{mmHg}$ and refractory to treatment), any infections within one month prior to the study, or major cardiovascular and cerebrovascular events (angina pectoris, heart failure, myocardial infarction, cerebral infarction, and cerebral hemorrhage) within the six months prior to the study $[5,6,14]$.

\section{Treatment plan}

During the two-week screening phase [6], patients with hypertension continued to receive the standard antihypertensive therapy. Patients who had been receiving angiotensin-I-converting enzyme inhibitors or angiotensinII-receptor antagonists were administered alternative medications (diuretics, calcium-channel antagonists, alpha- or beta-blockers, or a combination of these drugs) [5,6,14]. The blood pressure of all the patients was maintained at $<140 / 90 \mathrm{mmHg}$ [5]. The TwHF extract tablets used in this study were manufactured from the same species (Tripterygium wilfordii Hook F) as that used by GoldbachMansky et al. [10]. This medicine (10 mg/tablet) was produced by Jiangsu General Pharmaceuticals Co, Ltd, Taizhou, China and was approved by the State Food and Drug Administration (SFDA) of China.

The patients were randomly assigned to two groups. The TwHF group received $120 \mathrm{mg}$ of TwHF per day (one 40-mg tablet three times daily) for three months, followed by $60 \mathrm{mg}$ of TwHF per day (one 20-mg tablet three times daily) for the remaining three months. The valsartan group received $160 \mathrm{mg}$ of valsartan per day (Novartis, two 80-mg capsules once daily) for six months.

During the first three months of TwHF treatment, if liver function impairment or a WBC count $<3.0 \times 10^{9} / \mathrm{L}$ occurred, the dose was decreased to $60 \mathrm{mg} / \mathrm{d}$ for one week. If the patient recovered, then treatment with $60 \mathrm{mg} / \mathrm{d}$ TwHF continued. Otherwise, the treatment was discontinued, and the patient was excluded from the study. If a patient developed a severe infection, the TwHF treatment was halted, and the patient was withdrawn from this study. If the infection was resolved within two weeks, then observation continued, but the baseline information would be reevaluated. The dosage of valsartan was decreased to $80 \mathrm{mg} / \mathrm{d}$ if either the serum creatinine level increased by $50 \%$ and $>2 \mathrm{mg} / \mathrm{dl}$ or severe hyperkalemia $\left(\mathrm{K}^{+}>6.0 \mathrm{mmol} / \mathrm{L}\right)$ was observed. The valsartan treatment was discontinued if the above conditions were not controlled by additional treatments. Patients in either group were also excluded from the study if the treatment was discontinued for more than three weeks for any reason.

Throughout the study, the patients received routine care for DM, including measurements of glycosylated hemoglobin (HbA1c) and fasting serum glucose concentrations. The goals of the DM treatment included the maintenance of fasting blood glucose (FBG) levels $<7.0 \mathrm{mmol} / \mathrm{L}$, postprandial blood glucose (PBG) levels $<10.0 \mathrm{mmol} / \mathrm{L}$, and HbA1c levels $<7.0 \%$ [15]. Other treatments, such as diuresis to improve edema and albumin infusions, were performed in parallel. However, these treatments were discontinued at least three days prior to the measurement of urinary protein level. No restrictions on dietary salts or proteins were mandated. 


\section{Evaluation of response}

Follow-up evaluations were scheduled at one, three, and six months after the randomization (or more frequently, if necessary) to monitor blood pressure, laboratory measurements, and adverse events, as well as to assess end points. Two 24-h urine specimens were obtained over two consecutive days at baseline and one, three, and six months after randomization, and the two-day urine protein measurements were averaged. At baseline and at each follow-up visit, the vital signs and laboratory test results were evaluated, including complete blood count, FBG, blood urea nitrogen (BUN), serum creatinine, estimated glomerular filtration rate (eGFR), serum potassium, serum aspartate aminotransferase, alanine aminotransferase, urinalysis, and 24-h urine protein levels. The 24-h urine protein levels were measured via the trichloroacetic acid method using a photometer [16]. The serum creatinine concentrations were determined by the Jaffe reaction [17]. The Modification of Diet in Renal Disease (MDRD) formula was used to determine the eGFR [18]. The HbA1c levels were measured with high-performance liquid chromatography [19]. All the other laboratory parameters were assessed using conventional laboratory methods. The blood pressure was measured twice while the patient was seated, after at least 15 min of rest, using a standard mercury sphygmomanometer and an appropriately sized cuff. The mean value was calculated for each pair of measurements.

Renal dysfunction was indicated by a serum creatinine level $>1.5 \mathrm{mg} / \mathrm{dl}$, and the progression of renal dysfunction was defined as an increase in serum creatinine of $\geq 25 \%$ of the baseline value. The primary measure of treatment efficacy was a reduction in the 24-h urine protein level from baseline until the end of the study period (six months), and the secondary measure of efficacy was a reduction in the eGFR [5,14]. The end points were defined as a doubling of the serum creatinine concentration, the development of ESRD, cardiovascular or cerebrovascular events, or death [6]. The doubling of serum creatinine was defined as a level at the end of the study period that was twice the baseline level and higher than $5 \mathrm{mg} / \mathrm{dl}$. ESRD was defined as serum creatinine $>6 \mathrm{mg} / \mathrm{dl}$, eGFR $<15 \mathrm{ml} / \mathrm{min} / 1.73 \mathrm{~m}^{2}$, or the necessity of long-term dialysis [6].

We contacted the patients who did not return for clinical visits to inquire about the reasons for their failure to participate in follow-up, whether they had continued taking the medication, and whether they had reached the study end points.

\section{Statistical analysis}

In our pre-trial, the urine protein level in the TwHF group decreased by $52.2 \%$, whereas the level in the valsartan group decreased by $<10 \%$. A sample size of 46 patients (23 per group) was estimated to be sufficient to provide $80 \%$ statistical power to detect a two-sided level of significance of 0.05 at the primary end point. The data are expressed as the mean values \pm standard deviation (SD). Student's t-test, paired t-test, and repeatedmeasures analysis of variance (ANOVA) were used for between-group comparisons with adjustment for baseline values, as appropriate. Bonferroni correction was performed in t-test analysis. The differences in the urine protein, blood pressure, serum creatinine, serum albumin, and eGFR measurements between baseline and after one, three, and six months of treatment were analyzed by paired $\mathrm{t}$-test, and repeated measures ANOVA was used for the comparisons between TwHF and valsartan group during the follow-ups. The qualitative data are expressed as percentages and were analyzed using the chi-square $\left(\chi^{2}\right)$ or Fisher's exact test, as indicated. The correlations between a decrease in the urine protein level at the end of study period and the blood pressure, urine protein, serum creatinine, and eGFR measurements at baseline were analyzed using the bivariate correlations test. The multiple imputations method and a "pessimistic" analysis were used to assess the impact of missing values. The p-values reported were two-sided, and a p-value $<0.05$ was considered statistically significant. All the analyses were performed using SPSS software (version 11.0, SPSS Inc., USA).

\section{Results}

\section{Patient characteristics}

A total of 106 patients were screened at enrollment, and 41 patients were excluded. The remaining 65 patients were randomized to the TwHF group (34 patients) or the valsartan group (31 patients) and were followed up for at least six months. In the TwHF group, one patient who presented with a WBC count $<2.5 \times 10^{9} / \mathrm{L}$ was withdrawn from the study, and four other patients were lost to follow-up. In the valsartan group, one patient was withdrawn due to recurrent, severe hyperkalemia $\left(\mathrm{K}^{+}>\right.$ $6.5 \mathrm{mmol} / \mathrm{L}$ ), and four other patients were lost to followup [Figure 1]. The baseline characteristics of the two treatment groups were comparable [Table 1].

\section{Clinical response and adverse events}

The urine protein levels in the TwHF group decreased dramatically throughout the follow-up period. The reductions from baseline after one, three, and six months of treatment were $32.9 \%, 38.8 \%$, and $34.3 \%$, respectively. In contrast, the urine protein levels in the valsartan group remained relatively stable, with reductions at months one, three, and six of $1.05 \%, 10.1 \%$, and $-11.7 \%$, respectively $(\mathrm{p}<0.001)$ [Figure $2 \mathrm{~A}$ ]. The changes in the blood pressure, urine protein, serum albumin, serum creatinine, and eGFR during the follow-up period are 


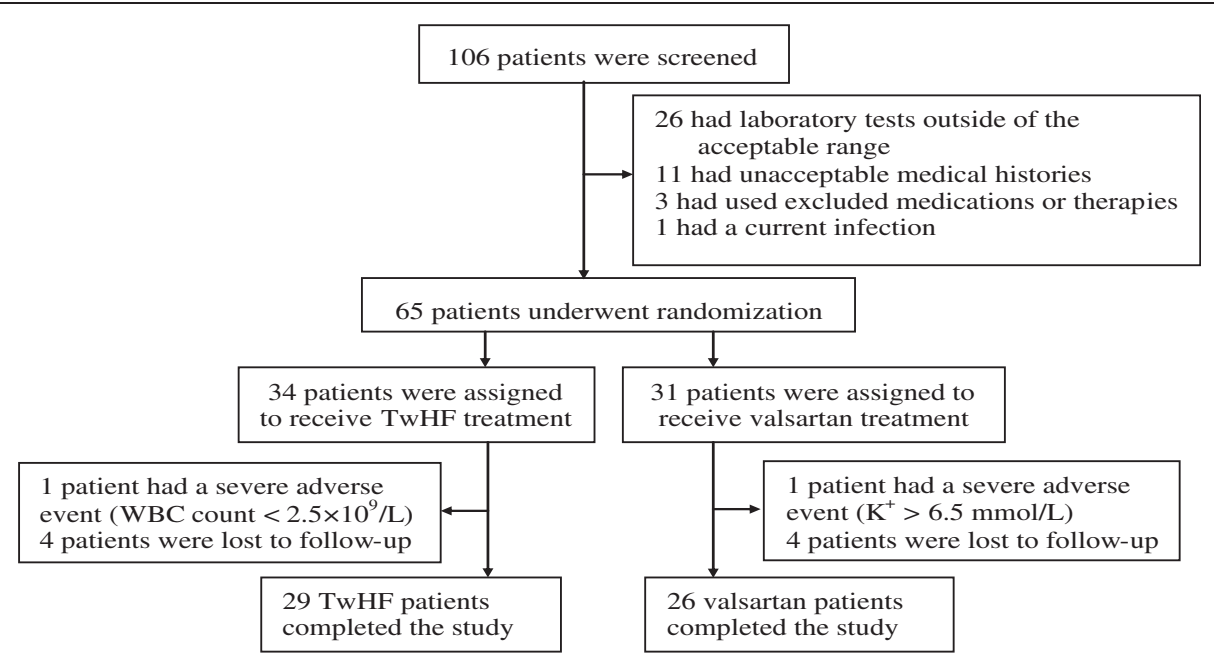

Figure 1 Flowchart of the treatment of DN with TwHF or valsartan.

shown in Table 2. However, there were no significant changes in the serum albumin levels in the TwHF group during the treatment. The mean decreases in eGFR during the six-month treatment period were $26.4 \%$ in the valsartan group and $13.7 \%$ in the TwHF group ( $\mathrm{p}=0.067)$ [Figure 2B].

At months three and six, the proportions of patients exhibiting DN disease progression (as evidenced by serum creatinine levels $\geq 25 \%$ higher than baseline) were significantly lower in the TwHF group than in the valsartan group $(18.18 \%$ vs. $48.00 \%$ at month three, respectively, $\mathrm{p}=0.022$ and $27.59 \%$ vs. $69.23 \%$ at month six, respectively, $\mathrm{p}=0.003$ ) [Figure 3].
A reduction in urine protein $\geq 50 \%$ and an increase in serum creatinine $<50 \%$ compared with baseline were observed in $31.03 \%$ (9 of 29) of the TwHF patients compared with $11.54 \%$ (3 of 26) of the valsartan patients $(p=0.076)$. When the data from the TwHF and valsartan groups were combined, a reduction in urine protein was correlated with the baseline diastolic blood pressure $(\mathrm{P}=0.021, \mathrm{R}=-0.33)$ but not with the baseline systolic blood pressure, serum creatinine, urine protein, or eGFR.

A total of ten patients (five in the TwHF group and five in the valsartan group) failed to complete the follow-up evaluations due to loss of contact or severe

Table 1 The baseline characteristics of the patients in both groups

\begin{tabular}{|c|c|c|c|}
\hline & TwHF group & Valsartan group & $\mathrm{p}$ \\
\hline Male: female & 20:14 & $17: 14$ & 0.805 \\
\hline Age (years) & $51.9 \pm 9.8$ & $51.0 \pm 8.9$ & 0.784 \\
\hline Duration of DM (months) & $126.9 \pm 68.1$ & $106.8 \pm 57.3$ & 0.270 \\
\hline Duration of DN (months) & $33.8 \pm 30.6$ & $26.1 \pm 28.4$ & 0.277 \\
\hline ACEI or ARB treatment before the screening phase $(n, \%)$ & $17,50 \%$ & $10,32.3 \%$ & 0.208 \\
\hline Systolic blood pressure $(\mathrm{mmHg})$ & $140.6 \pm 15.8$ & $138.3 \pm 17.1$ & 0.515 \\
\hline Diastolic blood pressure $(\mathrm{mmHg})$ & $81.6 \pm 11.9$ & $84.4 \pm 11.1$ & 0.233 \\
\hline FBG (mmol/L) & $6.04 \pm 1.51$ & $6.70 \pm 1.62$ & 0.092 \\
\hline Glycosylated hemoglobin (\%) & $6.26 \pm 1.15$ & $6.68 \pm 1.26$ & 0.202 \\
\hline Serum albumin $(g / L)$ & $33.0 \pm 5.66$ & $33.07 \pm 4.74$ & 0.988 \\
\hline Total cholesterol (mmol/L) & $6.08 \pm 1.96$ & $5.92 \pm 2.21$ & 0.702 \\
\hline Triglycerides (mmol/L) & $1.85 \pm 0.83$ & $2.50 \pm 2.10$ & 0.111 \\
\hline Serum creatinine (mg/dl) & $1.92 \pm 0.72$ & $1.67 \pm 0.62$ & 0.117 \\
\hline $\operatorname{eGFR}\left(\mathrm{ml} / \mathrm{min} / 1.73 \mathrm{~m}^{2}\right)$ & $43.07 \pm 21.65$ & $47.72 \pm 20.34$ & 0.377 \\
\hline Serum creatinine $>1.5 \mathrm{mg} / \mathrm{dl}(\%)$ & $70.6 \%$ & $54.8 \%$ & 0.210 \\
\hline Urine protein (g/24 h) & $4.99 \pm 2.25$ & $4.15 \pm 1.29$ & 0.097 \\
\hline
\end{tabular}



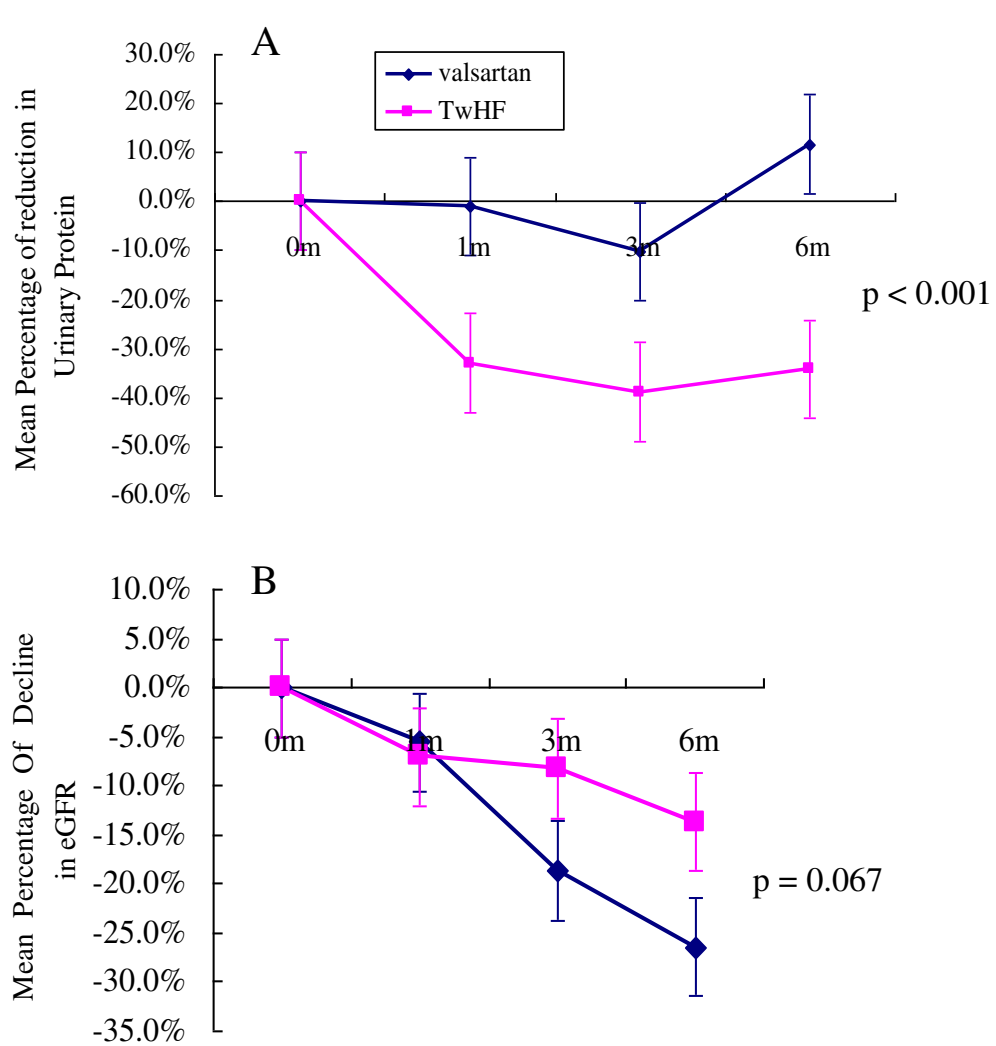

Figure 2 Changes in the baseline 24-h urine protein and eGFR levels over the six months of TwHF and valsartan treatments. A: The reductions in the urine protein levels of the available patients, expressed as the mean percentages of urine protein reduction compared with the baseline levels; $\mathbf{B}$ : The mean reductions in the eGFR values of the available patients, expressed as the mean percentages of eGFR reduction compared with the baseline. Each error bar represents the standard deviation from the mean value. The statistical analysis was performed using repeated-measures ANOVA. (TwHF group vs. valsartan group).

adverse events. A multiple imputations analysis was performed to assess the impact of the missing values. The recalculated reductions in proteinuria from baseline were $32.2 \%, 39.1 \%$, and $34.1 \%$, after one, three, and six months of TwHF treatment, respectively, percentages nearly identical to those obtained when the subjects lacking proteinuria data were omitted. The recalculated reductions in eGFR from baseline were $6.75 \%, 8.71 \%$, and $14.8 \%$ in the TwHF group, compared with $6.40 \%$, $18.5 \%$, and $27.2 \%$ in the valsartan group after one, three, and six months of treatment, respectively. The results of the pessimistic analysis, which imputed the missing

Table 2 Changes in the clinical characteristics of the patients in the TwHF group and valsartan group during the follow-up period

\begin{tabular}{|c|c|c|c|c|c|c|c|c|c|c|c|}
\hline & \multicolumn{2}{|c|}{ Baseline } & \multicolumn{2}{|c|}{ Month 1} & \multicolumn{2}{|c|}{ Month 3} & \multicolumn{2}{|c|}{ Month 6} & \multicolumn{3}{|c|}{$\begin{array}{l}\mathrm{P} \text { value calculated by } \\
\text { repeated-measures } \\
\text { ANOVA }\end{array}$} \\
\hline & $\begin{array}{c}\text { TwHF } \\
(n=34)\end{array}$ & $\begin{array}{c}\text { Valsartan } \\
(n=31)\end{array}$ & $\begin{array}{l}\text { TwHF } \\
(n=33)\end{array}$ & $\begin{array}{c}\text { Valsartan } \\
(n=29)\end{array}$ & $\begin{array}{l}\text { TwHF } \\
(n=33)\end{array}$ & $\begin{array}{c}\text { Valsartan } \\
(n=25)\end{array}$ & $\begin{array}{c}\text { TwHF } \\
(n=29)\end{array}$ & $\begin{array}{c}\text { Valsartan } \\
(n=26)\end{array}$ & Time & Group & $\begin{array}{l}\text { Time } \times \\
\text { Group }\end{array}$ \\
\hline $\begin{array}{c}\text { Systolic blood } \\
\text { pressure }(\mathrm{mmHg})\end{array}$ & $140.6 \pm 15.8$ & $138.4 \pm 16.6$ & $135.1 \pm 14.3$ & $139.4 \pm 16.2$ & $137.9 \pm 14.6$ & $138.6 \pm 19.7$ & $137.4 \pm 14.4$ & $141.9 \pm 18.4$ & 0.455 & 0.943 & 0.408 \\
\hline $\begin{array}{l}\text { Diastolic blood } \\
\text { pressure }(\mathrm{mmHg})\end{array}$ & $81.6 \pm 11.9$ & $85.0 \pm 10.8$ & $79.8 \pm 10.3$ & $78.7 \pm 10.3$ & $79.1 \pm 10.0$ & $77.7 \pm 8.8$ & $79.5 \pm 8.5$ & $76.5 \pm 10.5 \dagger$ & 0.03 & 0.574 & 0.253 \\
\hline Urine protein ( $g / 24 \mathrm{~h}$ ) & $4.99 \pm 2.25$ & $4.15 \pm 1.29$ & $3.23 \pm 2.57^{* * \#}$ & $3.92 \pm 1.56$ & $2.83 \pm 1.57^{* * \#}$ & $3.59 \pm 1.71$ & $2.99 \pm 1.81^{* * \#}$ & $4.40 \pm 2.37$ & $<0.001$ & 0.115 & 0.001 \\
\hline Serum albumin $(g / L)$ & $33.0 \pm 5.66$ & $33.0 \pm 4.69$ & $33.2 \pm 5.35 \#$ & $37.7 \pm 4.25 \neq$ & $33.9 \pm 5.3$ & $37.4 \pm 4.64 \ddagger$ & $34.8 \pm 5.49$ & $36.3 \pm 5.47 \neq$ & $<0.001$ & 0.368 & $<0.001$ \\
\hline $\operatorname{eGFR}\left(\mathrm{ml} / \mathrm{min} / 1.73 \mathrm{~m}^{2}\right)$ & $43.07 \pm 21.65$ & $47.72 \pm 20.34$ & $38.82 \pm 19.93$ & $43.59 \pm 17.41$ & $40.23 \pm 22.24$ & $39.33 \pm 16.79 \neq$ & $38.71 \pm 23.66^{*}$ & $36.22 \pm 14.96 \neq$ & $<0.001$ & 0.682 & 0.009 \\
\hline
\end{tabular}

${ }^{*} \mathrm{p}<0.05$ vs. TwHF baseline; ** $p<0.01$ vs. TwHF baseline.

$+p<0.05$ vs. Valsartan baseline; $\neq p<0.01$ vs. Valsartan baseline.

$\# p<0.05$ vs. Valsartan group at the same follow-up. 


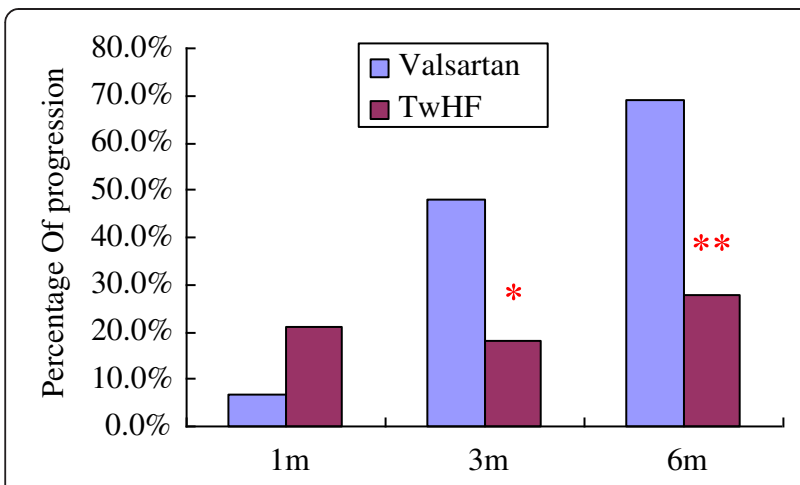

Figure 3 The incidence of renal disease progression during the follow-up period. ${ }^{*} p=0.022$ and ${ }^{* *} p=0.003$ for the TwHF and valsartan groups, respectively.

proteinuria values as double the last observed value for the TwHF patients, but equal to the last value for the valsartan patients, indicated reductions in proteinuria of $29.0 \%, 38.8 \%$, and $26.8 \%$ at one, three, and six months, respectively. The proteinuria reductions in the TwHF group were significantly greater than those in the valsartan group. When the missing eGFR values were imputed as half of their last observed value for the TwHF patients, but equal to their last value for the valsartan patients, the reductions in eGFR were $7.08 \%$, 9.61\%, and $20.3 \%$ in the TwHF group, compared with $5.21 \%, 15.4 \%$, and $28.3 \%$ in the valsartan group at one, three, and six months, respectively ( $\mathrm{p}>0.05)$.

The overall incidence of adverse events was $38.4 \%$ in the TwHF group, which was nearly identical to the $38.7 \%$ incidence observed in the valsartan group. Hyperkalemia necessitated a discontinuation of treatment in one patient (3.22\%) in the valsartan group. Treatment was also discontinued for one patient (2.94\%) in the TwHF group due to a reduction in the WBC count $\left(<2.5 \times 10^{9} / \mathrm{L}\right)$. Liver function impairment was observed in three patients in the TwHF group. After their TwHF dose was reduced to $60 \mathrm{mg}$ per day, these three patients recovered and finished the trial. Hyperkalemia was observed in eight patients in the TwHF group (with $\mathrm{K}^{+}>6.0 \mathrm{mmol} / \mathrm{L}$ in three patients) and in ten patients in the valsartan group (with $\mathrm{K}^{+}>6.0 \mathrm{mmol} / \mathrm{L}$ in two patients). A doubling of the serum creatinine was found in only one patient, who was in the valsartan group. There were no deaths in either group during the follow-up period [Table 3]. The anti-fertility effects of the TwHF extract were not evaluated because the majority of the patients were older than 50 , and patients attempting to conceive had been excluded from the study.

\section{Discussion}

DN is one of the most severe complications of type 2 DM and a major cause of ESRD. The urine protein level
Table 3 Adverse events during the follow-up period

\begin{tabular}{ccc}
\hline & $\begin{array}{c}\text { TwHF group } \\
(\mathbf{n}=\mathbf{3 4 )}\end{array}$ & $\begin{array}{c}\text { Valsartan group } \\
(\mathbf{n}=\mathbf{3 1})\end{array}$ \\
\hline Any adverse event $(n, \%)$ & $13(38.3)$ & $12(38.7)$ \\
Vomiting $(n, \%)$ & $1(2.94)$ & $0(0.00)$ \\
Liver dysfunction $(n, \%)$ & $3(8.82)$ & $0(0.00)$ \\
Decrease in WBC count $(n, \%)$ & $1(2.94)$ & $0(0.00)$ \\
Photosensitive dermatitis $(n, \%)$ & $0(0.00)$ & $1(3.22)$ \\
Hyperkalemia $(n, \%)$ & $8(23.53)$ & $10(32.2)$ \\
$K^{+}>6.0(n, \%)$ & $3(8.82)$ & $2(6.45)$ \\
Doubling of serum creatinine $(n, \%)$ & $0(0.00)$ & $1(3.22)$ \\
\hline
\end{tabular}

not only reflects the degree of renal injury but is also an independent risk factor for the progression of renal disease to ESRD. Increasing numbers of clinical trials have reported a strong association between the baseline level of proteinuria and a decline in eGFR $[5,6,20,21]$. As a result, urine protein is an important prognostic predictor, and decreased urine protein levels have been considered as a goal of DN treatment.

There were growing evidences indicated that immunologic and inflammatory mechanisms play important roles in the development and progression of $\mathrm{DN}[22,23]$. Inflammatory cytokines such as IL-1, IL-6, IL-18, TNF- $\alpha$, TGF- $\beta$, and MCP- 1 have been found to be involved in the pathophysiological processes of DN [22]. High glucose levels, abnormal hemodynamics, immune and inflammatory reactions, and injury of the glomerular basement membrane and podocytes constitute the pathophysiological basis of proteinuria. Indeed, our previous studies have revealed podocyte loss, foot process fusion, slit membrane effacement, the absence of nephrin expression, and the downregulation of WT1 in the glomeruli of DN patients $[24,25]$. In this regard, apart from strict glycemic control [26], ARBs have been demonstrated to be an effective therapeutic modality for DN $[5,6,14,27,28]$. The efficacy of ARBs is likely due to their ability to block RAS, to lower blood pressure, to suppress the expression of certain inflammatory cytokines [29], and to protect podocytes $[30,31]$. Considering the side effects of these drugs, which include hyperkalemia and increased serum creatinine, they are not appropriate for all patients, at least at the currently prescribed dosages. Thus, it is necessary to develop new medications for $\mathrm{DN}$ patients with proteinuria.

Previously, we have explored that TwHF extract elicits immune suppressive and anti-inflammatory effects, whereas triptolide potently inhibits NF- $\mathrm{kB}$ and the activation of $\mathrm{T}$ lymphocytes, as well as promoting apoptosis in activated $\mathrm{T}$ lymphocytes [9]. In addition, TwHF can attenuate oxidative stress and inhibit the expression of certain inflammatory cytokines (TNF- $\alpha$, IL-1 $\beta$, IL-6, and IFN- $\gamma$ ) [32]. More recently, we further demonstrated that 
triptolide could protect podocytes against puromycin aminonucleoside-induced injury both in vivo and in vitro, in addition to preventing proteinuria in treated animals [11]. We also found that in cultured murine podocytes, triptolide pretreatment prevented the puromycin-induced disruption of the actin cytoskeleton and microfilamentassociated synaptopodin, as well as preventing reductions in nephrin and podocin expression [11,12]. Based on the observed immunosuppressive, anti-inflammatory, and podocyte-protective effects of TwHF extract, we tested the efficacy of TwHF extract in treating diabetic $\mathrm{db} / \mathrm{db}$ mice and found that albuminuria was markedly attenuated, which was accompanied by an amelioration of glomerular hypertrophy and podocyte injury after triptolide treatment. In addition, we found that the effects of triptolide on renal inflammation and oxidative stress were more profound than those of valsartan [13].

Based on these findings, this prospective, randomized, controlled clinical trial was designed to evaluate the clinical therapeutic efficacy and safety of TwHF extract in patients with $\mathrm{DN}$. We found that the urine protein level could be significantly reduced by TwHF extract. At the end of the trial, the reduction of urine protein in the TwHF group was $34.3 \%$, which was significantly greater than the valsartan group. In addition, the decline in kidney function in the patients receiving TwHF treatment tended to be smaller than that observed in the valsartantreated patients.

Interestingly, although the urine protein levels were dramatically reduced in the TwHF group, the serum albumin levels did not increase significantly. We speculate that TwHF extract may interfere with the synthesis of albumin; further studies are required to reveal the underlying mechanism.

In this study, an ARB (valsartan) appeared less effective in reducing urine protein levels compared with previous, multicenter trials [5,6]; the urine protein levels in our valsartan group were reduced by only $1.05 \%$ and $10.1 \%$ at months one and three, respectively, and they tended to increase at month six. This discrepancy might be attributed to the following explanations: 1) seven patients could not tolerate the $160-\mathrm{mg} / \mathrm{d}$ valsartan dose due to hyperkalemia and increased serum creatinine; therefore, they switched to a lower dose of $80 \mathrm{mg} / \mathrm{d}$. In contrast, the participants in the RENAAL (losartan $100 \mathrm{mg} / \mathrm{d}$ ) and IDNT (irbesartan $300 \mathrm{mg} / \mathrm{d}$ ) trials tolerated higher doses of ARBs. 2) The RENAAL and IDNT trials evaluated the efficacy of losartan or irbesartan rather than valsartan; the therapeutic efficacies of these different ARBs might be distinct. 3) Our inclusion criteria were different from those in the abovementioned trials: our enrollment criterion for proteinuria was $\geq 2.5 \mathrm{~g} / 24 \mathrm{~h}$, and the mean urine protein was $4.15 \pm 1.29$ (2.51-7.65) $\mathrm{g} / 24 \mathrm{~h}$ in the valsartan group, which was significantly higher than that in the RENAAL (urine albumin/creatinine $1,237 \pm 1,261 \mathrm{mg} / \mathrm{g} . \mathrm{cr}$ ) and IDNT (median urine protein $2.9(1.6-5.4) \mathrm{g} / 24 \mathrm{~h}$ ) trials. 4) This study investigated the short-term efficacy of TwHF and valsartan treatments with a follow-up period of six months, which was significantly shorter than those of the previous studies.

The target level of blood pressure was $<140 / 90 \mathrm{mmHg}$, however, during the follow-ups, 35\% patients in TwHF group and $41 \%$ patients in valsartan group did not reach the target level. This discrepancy might be mostly attributed to the high percentage (63\%) of the patients suffered from chronic renal insufficiency. Although the blood pressure did not touch the target, the systolic blood pressure and diastolic blood pressure levels between two groups either at the baseline or during the follow-ups did not show significant difference. So it is not a major factor that impacts the efficacy judgement.

Regarding eGFR, Nelson et al. have reported that diabetic Pima Indians with macroalbuminuria demonstrated eGFR declines of only $1 \mathrm{ml} / \mathrm{min} / 1.73 \mathrm{~m}^{2}$ per month over a four-year period [33], in contrast to the larger change in eGFR over the six-month study period in this trial. This discrepancy might be attributed to the proteinuria and serum creatinine levels of the patients of this study, which were both significantly higher than those in the Nelson et al. study. Moreover, most of the patients enrolled in our trial were in the late stages of $\mathrm{DN}$, whereas in the study by Nelson et al., all of the patients presented with normal renal function.

Because ten patients were withdrawn from the present study, we conducted several analyses to specifically assess the impact of the missing data, including a multiple imputations analysis and a pessimistic analysis of the missing values. The qualitative and quantitative proteinuria results of these two analyses were similar to those of the primary analyses (with the missing values omitted). We also recalculated the eGFR values using these two methods. Based on these exploratory analyses, we concluded that the missing values due to patient withdrawal produced no significant impact on our conclusions concerning the primary efficacy of the TwHF extract treatment evaluated in this clinical trial.

In previous clinical trials of TwHF, the major adverse events included nausea, vomiting, loss of appetite, decreased WBC count, and liver function impairment $[7,8]$. Several Studies have reported the potential mechanisms of hepatoxicity and leucopenia induced by TwHF [34-36]. In this trial, we found that the TwHF extract dose of $120 \mathrm{mg} / \mathrm{d}$ was well tolerated by the majority of the patients. Although some adverse events occurred in the TwHF group, their incidence was comparable to that observed in the valsartan group. Previous clinical trials have also reported detrimental effects of TwHF extract 
on the genital system [8], including menstrual disorders in female patients. However, these effects were not observed in this trial, which was largely due to the older age (> 50 years) of the majority of the female patients.

This trial was limited by the following factors: 1) it was a single-center trial with a small sample size and a relatively short follow-up period, 2) the treatment assignment was not blinded, 3) the rate of subject withdrawal during the follow-up period was $>10 \%$, and 4 ) a reduction in the 24-h urine protein level was used as a surrogate end point. Thus, a multicenter, blinded, longterm study is needed to confirm the renoprotective effects of TwHF extract in patients with DN.

\section{Conclusions}

In conclusion, TwHF extract can reduce the urine protein levels of patients with DN and thus represents a novel, potentially effective, and safe renoprotective drug for the treatment of DN. TwHF extract may play an important role in multidrug regimens for the treatment of $\mathrm{DN}$.

\section{Abbreviations}

DN: Diabetic nephropathy; ARBs: Angiotensin II receptor blockers; TwHF: Tripterygium wilfordii Hook F; DM: Diabetes mellitus; eGFR: Estimated glomerular filtration; ESRD: End-stage renal disease; RAS: Renin-angiotensin system; WBC: White blood cell; HbA1c: Glycosylated hemoglobin; FBG: Fasting blood glucose; PBG: Postprandial blood glucose; BUN: Blood urea nitrogen; MDRD: Modification of diet in renal disease; SD: Standard deviation; ANOVA: Analysis of variance; TW: Tripterygium wilfordii.

\section{Competing interests}

The authors declare that they have no competing interests.

\section{Authors' contributions}

YC Ge conceived the study, participated in its design and coordination, and drafted the manuscript. HL Xie and SJ Li interpreted the data and helped to draft the manuscript. B Jin, JH Hou, and HT Zhang participated in the design of the study and performed the statistical analyses. MJ Shi performed the laboratory experiments. ZH Liu supervised the study and participated in its design. All the authors read and approved the final manuscript.

\section{Acknowledgments}

The authors thank Dr. Jianling Bai and Minlin Zhou for assistance with the statistical analyses. We also thank Prof. Shao-Lin Shi and Dr. Song Jiang for editorial assistance.

Received: 27 February 2013 Accepted: 17 May 2013

Published: 31 May 2013

\section{References}

1. Yang W, Lu J, Weng J, Jia W, Ji L, Xiao J, Shan Z, Liu J, Tian H, Ji Q, China National Diabetes and Metabolic Disorders Study Group, et al: Prevalence of diabetes among Men and women in China. N Engl J Med 2010, 362:1090-1101.

2. Jin B, Liu ZH, Ge YC, Xie HL, Wang SF, Fu YJ, Li LS: Changes of epidemiologic character in patients with diabetic nephropathy received renal biopsy. Chin J Nephrol Dial and Transplant 2009, 18:133-139. Chinese.

3. Remuzzi $G$, Ruggenenti $P$, Benigni A: Understanding the nature of renal disease progression. Kidney Int 1997, 51:2-15.

4. Yu HT: Progression of chronic renal failure. Arch Intern Med 2003, 153:1417-1429.

5. Brenner BM, Cooper ME, de Zeeuw D, Keane WF, Mitch WE, Parving HH, Remuzzi G, Snapinn SM, Zhang Z, Shahinfar S, RENAAL Study Investigators: Effects of losartan on renal and cardiovascular outcomes in patients with type 2 diabetes and nephropathy. N Engl J Med 2001, 345:861-869.
6. Lewis EJ, Hunsicker LG, Clarke WR, Berl T, Pohl MA, Lewis JB, Ritz E, Atkins RC, Rohde R, Raz I, Collaborative Study Group: Renoprotective effects of the angiotensin receptor antagonist irbesartan in patients with nephropathy due to type 2 diabetes. N Engl J Med 2001, 345:851-860.

7. Liu ZH, Li SH, Wu Y, Zuo K, Wang B, Zeng CH, Li LS: Treatment of membranous nephropathy with tripterygium wilfordii and steroid: a prospective randomized control trial. Chin J Nephrol Dial and Transplant 2009, 18:303-309. Chinese.

8. Ji SM, Wang QW, Chen JS, Sha GZ, Liu ZH, Li LS: Clinical trial of Tripterygium wilfordii Hook F. in human kidney transplantation in China. Transplant Proc 2006, 38:1274-1279.

9. Liu H, Liu ZH, Chen ZH, Yang JW, Li LS: Triptolide: a potent inhibitor of NF-KB in T-lymphocytes. Acta Pharmacol Sin 2000, 21:782-786.

10. Goldbach-Mansky R, Wilson M, Fleischmann R, Olsen N, Silverfield J, Kempf P, Kivitz A, Sherrer Y, Pucino F, Csako G, et al: Comparison of Triterygium wilfordii Hook $F$ versus Sulfasalazine in the treatment of Rheumatoid Arthritis: a randomized trial. Ann Intern Med 2009, 151:229-240.

11. Zheng CX, Chen ZH, Zeng CH, Qin WS, Li LS, Liu ZH: Triptolide protects podocytes from puromycinaminonucleoside induced injury in vivo and in vitro. Kidney Int 2008, 74:596-612.

12. Chen ZH, Qin WS, Zeng CH, Zheng CX, Hong YM, Lu YZ, Li LS, Liu ZH: Triptolide reduces proteinuria in experimental membranous nephropathy and protects against C5b-9-induced podocyte injury in vitro. Kidney Int 2010, 77:974-988.

13. Gao Q, Shen W, Qin W, Zheng C, Zhang M, Zeng C, Wang S, Wang J, Zhu X, Liu Z: Treatment of obese $\mathrm{db} / \mathrm{db}$ diabetic mice with triptolide: a novel therapy for diabetic nephropathy. Nephrol Dial Transplant 2010, 25:3539-3547.

14. Parving HH, Persson F, Lewis JB, Lewis EJ, Hollenberg NK, AVOID Study Investigators: Aliskiren Combined with Losartan in Type 2 Diabetes and Nephropathy. N Engl J Med 2008, 358:2433-2446.

15. Gross JL, de Azevedo MJ, Silveiro SP, Canani LH, Caramori ML, Zelmanovitz T: Diabetic nephropathy: diagnosis, prevention, and treatment. Diabetes Care 2005, 28(1):164-176.

16. Momeni A, Shahidi S, Seirafian S, Taheri S, Kheiri S: Effect of allopurinol in decreasing proteinuria in type 2 diabetic patients. Iran J Kidney Dis 2010, 4(2):128-132.

17. Bartels H, Böhmer M, Heierli C: Serum creatinine determination without protein precipitation. Clin Chim Acta 1972, 37:193-197.

18. Levey AS, Bosch JP, Lewis JB, Greene T, Rogers N, Roth D: A more accurate method to estimate glomerular filtration rate from serum creatinine: a new prediction equation. Ann Intern Med 1999, 130:461-470.

19. Rohlfing CL, Little RR, Wiedmeyer HM, England JD, Madsen R, Harris MI, Flegal KM, Eberhardt MS, Goldstein DE: Use of GHb (HbA1c) in screening for undiagnosed diabetes in the U.S. population. Diabetes Care 2000, 23:187-191.

20. Rossing P, Hommel E, Smidt UM, Parving HH: Reduction in albuminuria predicts a beneficial effect on diminishing the progression of diabetic nephropathy during antihypertention treatment. Diabetologia 1994, 37:511-516.

21. Lebovitz HE, Wiegmann TB, Cnaan A, Shahinfar S, Sica DA, Broadstone V, Schwartz SL, Mengel MC, Segal R, Versaggi JA: Renal protective effects of enalapril in hypertensive NIDDM: Role of baseline albuminuria. Kidney Int 1994, 45:S150-S155.

22. Navarro-González JF, Mora-Fernández C: The role of inflammatory cytokines in diabetic nephropathy. J Am Soc Nephrol 2008, 19:433-442.

23. Ortiz-Muñoz G, Lopez-Parra V, Lopez-Franco O, Fernandez-Vizarra P, Mallavia B, Flores C, Sanz A, Blanco J, Mezzano S, Ortiz A, et al: Suppressors of cytokine signaling abrogate diabetic nephropathy. J Am Soc Nephrol 2010, 21:763-772.

24. Su J, Li SJ, Chen ZH, Zeng CH, Zhou H, Li LS, Liu ZH: Evaluation of podocyte lesion in patients with diabetic nephropathy: Wilms' tumor-1 protein used as a podocyte marker. Diabetes Res Clin Pract 2010, 87(2):167-175.

25. Zhu WW, Chen HP, Ge YC, Xie HL, Zeng CH, Li LS, Liu ZH: Ultrastructural changes in the glomerular filtration barrier and occurrence of proteinuria in Chinese patients with type 2 diabetic nephropathy. Diabetes Res Clin Pract 2009, 86:199-207.

26. UK Prospective Diabetes Study (UKPDS) Group: Intensive blood-glucose control with sulphonylureas or insulin compared with conventional treatment and risk of complications in patients with type 2 diabetes. Lancet 1998, 352:837-853. 
27. Weidmann $P$, Boehlen $L M$, de Courten M: Effects of different antihypertensive drugs on human diabetic proteinuria. Nephrol Dial Transplant 1993, 8:582-584.

28. Hamilton RA, Kane MP, Demers J: Angiotensin-converting enzyme inhibitors and type 2 diabetic nephropathy: a meta-analysis. Pharmacotherapy 2003, 23:909-915.

29. Ogawa S, Mori T, Nako K, Kato T, Takeuchi K, Ito S: Angiotensin II type 1 receptor blockers reduce urinary oxidative stress markers in hypertensive diabetic nephropathy. Hypertension 2006, 47:699-705.

30. Wang G, Lai FM, Lai KB, Chow KM, Kwan BC, Li PK, Szeto CC: Urinary messenger RNA expression of podocyte-associated molecules in patients with diabetic nephropathy treated by angiotensin-converting enzyme inhibitor and angiotensin receptor blocker. Eur J Endocrinol 2008, 158:317-322.

31. Nishiyama A, Kobori H, Konishi Y, Morikawa T, Maeda I, Okumura M, Kishida M, Hamada M, Nagai Y, Nakagawa T, et al: Mineralocorticoid receptor blockade enhances the antiproteinuric effect of an angiotensin II blocker through inhibiting podocyte injury in type 2 diabetic rats. J Pharmacol Exp Ther 2010, 332:1072-1080.

32. Wu Y, Cui J, Bao X, Chan S, Young DO, Liu D, Shen P: Triptolide attenuate oxidative stress, NF-kB activation and multiple cytokine gene expression in murine peritoneal macrophage. Int J Mol Med 2006, 17:141-150.

33. Nelson RG, Bennett PH, Beck GJ, Tan M, Knowler WC, Mitch WE, Hirschman $\mathrm{GH}$, Myers BD: Development and progression of renal disease in pima Indians with non-insulin-dependent diabetes mellitus. Diabetic renal disease study group. N Engl J Med 1996, 335:1636-1642.

34. Zhang Y, Jiang Z, Xue M, Zhang S, Wang Y, Zhang L: Toxicogenomic analysis of the gene expression changes in rat liver after a 28-day oral Tripterygium wilfordii multiglycoside exposure. J Ethnopharmacol 2012, 141:170-177.

35. Yao J, Jiang Z, Duan W, Huang J, Zhang L, Hu L, He L, Li F, Xiao Y, Shu B, Liu C: Involvement of mitochondrial pathway in triptolide-induced cytotoxicity in human normal liver L-02 cells. Biol Pharm Bull 2008, 31:592-597.

36. Pyatt DW, Yang Y, Mehos B, Le A, Stillman W, Irons RD: Hematotoxicity of the Chinese herbal medicine tripterygium wilfordii hook $f$ in CD34positive human bone marrow cells. Mol Pharmacol 2000, 57:512-518.

doi:10.1186/1479-5876-11-134

Cite this article as: Ge et al.: Treatment of diabetic nephropathy with Tripterygium wilfordii Hook F extract: a prospective, randomized, controlled clinical trial. Journal of Translational Medicine 2013 11:134

\section{Submit your next manuscript to BioMed Central and take full advantage of:}

- Convenient online submission

- Thorough peer review

- No space constraints or color figure charges

- Immediate publication on acceptance

- Inclusion in PubMed, CAS, Scopus and Google Scholar

- Research which is freely available for redistribution 